\title{
Clinical ascertainment of Nijmegen breakage syndrome (NBS) and prevalence of the major mutation, 657del5, in three Slav populations
}

\author{
Raymonda Varon ${ }^{1}$, Eva Seemanova ${ }^{2}$, Krystyna Chrzanowska ${ }^{3}$, Oleg Hnateyko ${ }^{4}$, \\ Dorota Piekutowska-Abramczuk ${ }^{3}$, Malgorzata Krajewska-Walasek ${ }^{3}$, \\ Jolanta Sykut-Cegielska ${ }^{3}$, Karl Sperling ${ }^{1}$ and André Reis ${ }^{1,5}$
}

${ }^{1}$ Institute of Human Genetics, Charité, Humboldt-University, Berlin, Germany; ${ }^{2}$ Department of Medical Genetics, Charles University, Prague, Czech Republic; ${ }^{3}$ Department of Medical Genetics, Children's Memorial Health Institute, Warsaw, Poland; ${ }^{4}$ Scientific-Research Institute of Hereditary Pathology, Lvov, Ukraine; ${ }^{5}$ M olecular Genetics and Gene Mapping Centre, Max-Delbrueck-Centre, Berlin, Germany

\begin{abstract}
Nijmegen breakage syndrome (NBS) is a chromosomal instability disorder, clinically characterised by microcephaly, immunodeficiency, radiosensitivity and a very high predisposition to lymphoid malignancy. Recently, it was demonstrated that mutations in the NBS1 gene are responsible for NBS. Most of the NBS patients known so far are of Slav origin and carry a major founder mutation 657del5 in exon 6 of the NBS1 gene. In this study we estimated the prevalence of the 657del5 mutation in the Czech Republic, Poland and the Ukraine. We found an unexpectedly high carrier frequency of the 657del5 mutation (1/177) in the three Slav populations, a factor that may contribute to cancer frequency in those countries. In addition, we show that NBS patients are often diagnosed late and therefore receive inappropriate therapy. European Journal of Human Genetics (2000) 8, 900-902.
\end{abstract}

Keywords: NBS; 657del5; carrier frequency; Slav populations

\section{Introduction}

Recently, mutations in the gene coding for nibrin were shown to be responsible for Nijmegen breakage syndrome (NBS), a relatively rare chromosomal instability disorder clinically characterised by microcephaly, immunodeficiency, growth retardation and high susceptibility to lymphoid malignancy. ${ }^{1}$ Cells derived from NBS patients are hypersensitive to ionising radiation and exhibit a defect of cellcycle control. Nibrin is a member of the hMRE11/RAD50 protein complex which has been implicated in the repair of DNA double-strand breaks and recombination. ${ }^{2}$ The maj ority of NBS patients are of Slav origin and carry the major founder mutation 657del 5 in exon 6 of the NBS1 gene. We found this mutation on both chromosomes in 82 of 84 unrelated NBS patients analysed thus far, most of whom originate from

Correspondence: Professor Dr André Reis, Institut für Humangenetik, Charité, Humboldt University, Augustenburger Platz 1, 13353 Berlin, Germany. Tel: +493045066123; Fax: +493045066904; E-mail: andre.reis@charite.de

Received 19 April 2000; revised 11 July 2000; accepted 14 July 2000
Poland and the Czech Republic. Based on epidemiological data it has been suggested that NBS heterozygotes also have an elevated cancer risk, ${ }^{3}$ similar to that in another related chromosomal instability syndrome, ataxia telangiectasia (AT). Increased risk of cancer for AT heterozygotes, in particular of breast cancer, ${ }^{4}$ chronic lymphocytic leukaemia $(\mathrm{B}-\mathrm{CLL})^{5,6}$ and T-cell prolymphocytic leukaemia (T-PLL) ${ }^{7}$ has been described. Clinical and especially cell biology similarities between NBS and AT, combined with the existence of a single major NBS founder mutation prompted us to estimate the general population frequency of the 657 del 5 mutation in three Slav populations - the Czech, Polish and Ukranians and so to evaluate the potential impact of the suggested cancer risk for NBS heterozygotes.

\section{Materials and methods}

We analysed a total of 4416 randomly selected anonymous Guthrie cards drawn from newborn screening programmes 2274 from Poland, 1234 from the Czech Republic and 908 
from the Ukraine (Lvov region). All samples were analysed for the 657del 5 mutation by PCR-single strand conformation polymorphism (PCR-SSCP) analysis. A piece of approximately $2 \mathrm{~mm}$ in diameter was cut from each Guthrie card and used in a PCR reaction with fluorescently labelled (Fam) primers, flanking exon 6 of the NBS1 gene. The amplicons were electrophoresed on non-denaturing polyacrylamide gels as previously described. ${ }^{1}$ All positive samples were confirmed by direct sequencing.

\section{Results}

We found 25 carriers of the 657 del 5 mutation in 4416 Guthrie cards (Table 1), a mean prevalence of $1 / 177$ for the three populations tested. The highest prevalence of heterozygotes was found in the Czech population (1/154), whilst heterozygote frequencies for the Polish and the Ukrainian populations (Lvov region) were somewhat lower - 1/190 and $1 / 182$, respectively. These frequencies are much higher than $1 / 866$ recently reported for the same mutation in Germany. ${ }^{8}$

Mean age at diagnosis was around 7 years in both the Czech and the Polish patients (Table2). The leading symptom was microcephaly which was seen in all but one patient. One third of the Czech and $15 \%$ of the Polish patients had already manifest malignancies at diagnosis.

\section{Discussion}

Unexpectedly, we found a high carrier frequency for the 657 del5 mutation in the three Slav populations tested.

Table 1 Prevalence of the major NBS1 mutation, 657del5

\begin{tabular}{lrcl}
\hline Country & Newborns & Heterozygotes & Frequency \\
\hline Czech Republic & 1234 & 8 & $1: 154$ \\
Ukraine (Lvov region) & 908 & 5 & $1: 182$ \\
Poland & 2274 & 12 & $1: 190$ \\
$\quad$ of which: & & & \\
$\quad$ Nowy Sacz & 452 & 5 & $1: 90$ \\
$\quad$ Krakow & 1254 & 4 & $1: 314$ \\
$\quad$ Krosno & 568 & 3 & $1: 189$ \\
Total & 4416 & 25 & $1: 177$ \\
\hline
\end{tabular}

Table 2 NBS patient characteristics - age and principal symptoms at diagnosis

\begin{tabular}{lllll}
\hline Country & Age at & \multicolumn{3}{c}{ Principal symptoms at diagnosis } \\
& diagnosis & MC & NHL & Rl \\
\hline $\begin{array}{l}\text { Czechoslovakia } \\
n=16\end{array}$ & $7.1 \pm 4.5$ & $16(100 \%)$ & $6(37 \%)$ & $5(31 \%)$ \\
$\begin{array}{l}\text { Poland } \\
n=37\end{array}$ & $7.2 \pm 6.3$ & $36(97 \%)$ & $5(14 \%)$ & $17(46 \%)$ \\
\hline
\end{tabular}

MC: microcephaly; NHL: non-Hodgkin's lymphomas, mainly acute lymphoblastic leukemia; Rl: recurrent infections; $n$ : number of index patients.
However, marked regional differences were observed in the Polish sample, with the highest prevalence of heterozygotes found in the area of Nowy Sacz (1/90). Epidemiological data indicate that in Poland a total of 46 NBS patients from 37 families have been diagn osed during the last 20 years from 12 million recorded live births. The differing regional distribution of NBS heterozygotes allows no precise estimation of the incidence of expected homozygotes in Poland. The situation is different in the former Czechoslovakia, where 16 NBS families are randomly distributed (11 from Czechia and 5 from Slovakia). Moreover, the analysed pool of Guthrie cards can be considered representative for Czechia since it comprises samples originating from almost all parts of the country. Thus the incidence of NBS patients can be estimated at $1 / 95000$ live-births based on this carrier frequency.

The number of patients diagnosed is clearly lower than expected. In the period between 1981 and 1995, during which clinical ascertainment of NBS probands can be considered constant, a total of seven index cases from six families were diagnosed in Czechia from 1.9 million recorded live births. Due to delayed diagnosis however, only three were actually born in this period. If those four probands for whom diagnosis was made after 1995 are included, the number of cases resorts to seven. Thus, according to the rough calculation, the frequency of diagnosed NBS patients was $1 / 271000$, and clearly lower than expected (1/95000).

In principle, the observed discrepancy between the expected and observed number of NBS patients can be either due to selection against affected foetuses, reduced fertility of NBS gene carriers or underdiagnosis. The first two assumptions, however, are somewhat unlikely. The rate of spontaneous abortions in Polish and Czech NBS families with 6 in 107 or 1 in 55 pregnancies was even lower than in the general population with more than $10 \% .^{9}$ In addition, the mean number of children in these families was about three (37Polish and 16Czech NBS families with 107 and 55 children, respectively), which is not indicative of reduced fertility. Thus, the most likely explanation for the observed discrepancy is underdiagnosis. It can be explained by the rarity of the disease and its relatively mild phenotype. This assumption is supported by the late recognition of many NBS patients.

Table 2 shows that in former Czechoslovakia and Poland the mean age at diagnosis is $7.1 \pm 4.5$ and $7.2 \pm 6.3$, respectively. At that time, $14-37 \%$ of the NBS patients had al ready developed a tumour. The extreme radiosensitivity of NBS patients together with delayed diagnosis is a hidden danger, since patients with a malignancy are subjected to chemo- and radiotherapy which could lead to secondary tumours and even death. Therefore, it is absolutely essential to postulate criteria for the early and certain recognition of NBS in order to avoid the conventional treatment protocols in cases where a malignancy is already present. ${ }^{10}$ This must hold not only for the Slav populations studied, but also for NBS patients 
worldwide, although the frequency of the disorder is most probably lower than that reported here.

As mentioned above, not only are NBS patients predisposed to cancer, but heterozygous carriers of NBS1 mutations may have increased risk of cancer. ${ }^{3}$ This is supported by recent findings of decreased DNA stability and higher incidence of malignancy in heterozygous relatives of NBS patients of Slav origin (Novotna B, 1999) and by the association of NBS1 mutations with childhood acute lymphoblastic leukemia (Varon et $\mathrm{al}^{11}$ ). Therefore, carriers of NBS1 mutation should avoid ionising radiation and also receive modified treatment protocols in cases of malignancy.

In summary, this study provides the first data on frequencies of the 657 del 5 mutation in three Slav populations. We have also shown that the NBS patients are usually diagnosed late, which often gives rise to serious illness. The high incidence of the 657 del 5 mutation found here might be an important cancer risk factor for the Slav populations. The existence of a single mutation, however, offers an opportunity for easy and early detection of NBS patients and heterozygotes.

\section{Acknowledgements}

We are indebted to all patients for their participation in this study. We thank Professor Elleder and $\mathrm{Dr} \mathrm{T}$ Astna for providing the Czech Guthrie cards. We also thank Catrin Janetzki and Mohsen Karbasiyan for their excellent technical assistance and Martin Digweed for critical reading of the manuscript. This work was supported by grants from the Deutsche Forschungsgemeinschaft and Sander Stiftung to K Sperling and A Reis.

\section{References}

1 Varon R, Vissinga C, Platzer $M$ et al: Nibrin, a novel DNA doublestrand break repair protein, is mutated in Nijmegen breakage syndrome. Cell 1998; 93: 467-476.

2 Carney JP, Maser RS, Olivares $\mathrm{H}$ et al: The $\mathrm{hM}$ rell/hRad50 protein complex and Nijmegen breakage syndrome: linkage of doublestrand break repair to the cellular DNA damage response. Cell 1998; 93: 477-486.

3 Seemanova E: An increased risk for malignant neoplasms in heterozygotes for a syndrome of microcephaly, normal intelligence, growth retardation, remarkable facies, immunodeficiency and chromosomal instability. Mutat Res 1990; 238: 321-324.

4 Swift M, Reitnauer PJ, Morrell D et al: Breast and other cancers in families with ataxia-telangiectasia. N Engl J Med 1987; 316: 1289-1294.

5 Stankovic $T$, Weber $P$, Stewart $G$ et al: Inactivation of ataxia telangiectasia mutated gene in B-cell chronic lymphocytic leukaemia. Lancet 1999; 353: 26-29.

6 Reis A: Genetics and B-cell leukaemia. Lancet 1999; 353: 3.

7 Vorechovsky I, Luo L, Dyer MJ et al: Clustering of missense mutations in the ataxia-telangiectasia gene in a sporadic T-cell leukaemia. Nat Genet 1997; 17: 96-99.

8 Carlomagno F, Chang-Claude J, Dunning AM et al: Determination of the frequency of the common 657Del5 Nijmegen breakage syndrome mutation in the German population: no association with risk of breast cancer. Genes Chromosomes Cancer 1999; 25: 93-95.

9 Gustavii B: First-trimester chromosomal analysis of chorionic villi obtained by direct vision technique. Lancet 1983; 507-508.

10 Seidemann K, Tiemann M, Henze G et al: Therapy for nonHodgkin lymphoma in children with primary immunodeficiency: analysis of 19 patients from the BFM trials. Med Pediatr Oncol 1999; 33: $536-544$

11 Varon R, Reis A, Henze $G$ et al: Mutations in the nijmegen breakage syndrome gene (NBS1) in childhood acute lymphoblastic leukemia (ALL). Cancer Research (submitted). 